\title{
Are Levodopa “Drug Holidays” Justified?
}

\author{
Oscar S. Kofman
}

ABSTRACT: Complete withdrawal of all levodopa compounds "drug holiday" for a period of at least one week in severely disabled, unresponsive Parkinson patients may influence receptor blockade by resensitizing and can alter denervation hypersensitivity.

Twenty four patients with 31 holidays were evaluated. Transient improvement was noted in most patients, however significant long term benefit of over 1 years duration occurred in only 6 individuals.

In view of the unpredictability and limited responsiveness, drug holiday has not yet been established as a satisfactory treatment for the severe, intractable problems associated with chronic levodopa administration in Parkinson patients. Further trials appear to be warranted.

RÉSUMÉ: Le retrait total de toute Lévodopa, sous forme de congé thérapeutique d'une durée minimale d'une semaine, chez des Parkinson très atteints et non répondants peut influencer le bloc du récepteur en le resensitivant et peut modifier l'hypersensibilité de dénervation.

Nous avons évalué 24 patients et 31 congés thérapeutiques. Une amélioration temporaire fut notée chez la plupart des patients, cependant un bénéfice significatif à long terme sur une période excédant $I$ an ne fut noté que chez 6 individus.

A cause de la variabilité et de la limitation des réponses nous ne croyons pas que le congé thérapeutique soit encore établi comme approche valable des problèmes sévères et intraitables accompagnant l'administration chronique de Lévodopa.

Can. J. Neurol. Sci. 1984: 11:206-209

During the past 15 years, it has become clearly established that the treatment of Parkinson patients with levodopa alone or in combination with decarboxylase inhibitors such as carbidopa or benserazide, as well as dopamine agonists has generally been effective (Barbeau and McDowell, 1970; Kofman, 1971, 1983; Yahr, 1978). Unfortunately it has been common experience to encounter significant and at times intractable problems that appear to be related to chronic levodopa administration. These disabling problems and complications include a failure of drug response, presumably due to decrease in receptor response, on-off phenomena, dyskinesias and psychiatric disorders which include confusion, pseudodementia and hallucinosis (Marsden and Parkes, 1976; Ptcoch and Marsden, 1977).

The decline in effectiveness of these drugs generally develops after levodopa administration of several months duration and more often after one to five years, particularly if high dosage has been used.

Many patients have experienced some degree of improvement relative to these problems following significant reduction of the dopamine substances. However, an increasing number of persistent problems have been recognized despite attempts at medical adjustment or partial drug withdrawal.

\section{Drug Holiday Chronology}

Dating back to 1969 , we have seen and been aware of specific observations relative to patients who are withdrawn from levodopa therapy for various reasons including medical disorders such as coronary insufficiency, surgical procedures and, at times, noncompliance, who showed an increased response upon reinstitution of therapy. Since 1976, we have specifically utilized this method of complete withdrawal of levodopa compounds and dopamine agonists in the form of "drug holiday" in selected, severely disabled patients with stage 4 and occasionally stage 5 disease (Hoehn and Yahr classification) with intractable Parkinsonrelated therapeutic problems. Many individuals were specifically referred to us by other neurologists and physicians at a stage when they had exhibited a total failure of response to continued dopamine therapy in various combinations and after various unsuccessful attempts to adjust medication.

The first published report of an enhanced response to low doses of levodopa after withdrawal from chronic treatment was by Sweet et al. (1972). Seven of 13 Parkinson patients improved after a single $500 \mathrm{mg}$. dose of levodopa. This response began 20 to 120 minutes after the medication and lasted one to two hours. Improvement involved gait, bradykinesia and rigidity. Plasma dopa concentrations measured at that time did not differ significantly between those who responded and those who did not, suggesting that the mechanism of enhanced response after withdrawal may lie in the brain rather than in the peripheral metabolism. There were no reported follow up studies.

Reference to partial drug withdrawal was made by Direnfeld et al. (1978) with regard to one patient who had been treated with an extremely high dosage of Prolopa (a combination of $4400 \mathrm{mg}$. of levodopa with $1100 \mathrm{mg}$. of benserazide). Over a 33 day period, the dosage was lowered to $20 \%$ of the original amount following which adjustments were made until a consistent response was observed. The three main results that were achieved were first, overall reduction by $64 \%$ of the daily requirement for levodopa; second, conversion from a previously unpredictable to a predictable response to each dose of levodopa; and thirdly, change in movement fluctuations to a pattern that was more typical of end of dose akinesia rather than on-off phenomenon. The results appeared to support the idea of dopamine receptor resensitization upon reduction of levodopa dosage. 
Weiner et al. (1980) reported on the short term effects of a period of transient complete drug withdrawal, i.e. drug holiday, in 16 patients who manifested severe complications of chronic levodopa therapy. Eleven of the 16 patients exhibited enhanced motor responsiveness after the holiday and required only half of the initial dose for improved motor performance. Most levodopa induced side affects decreased after the holiday. Hallucinosis was ameliorated in all cases. The frequency of on-off phenomena and myoclonus also diminished. Dyskinesias were improved, presumably because of the lower dose requirement.

A 1 year follow up of this study by Koller et al. (1981) referred to 14 of the initial 16 patients. The data indicated that many individuals who had increased motor responsiveness immediately after the holiday experienced gradual increase in parkinsonian symptoms and signs during the next year. In general, significant deterioration did not occur before six months after the holiday and several patients retained some benefit after one year. Rigidity appeared to be the manifestation that remained improved for the longest period. Drug holidays were most beneficial for psychiatric complications. At the end of one year, 4 of the 6 patients remained free of hallucinosis. On-off phenomena returned in one of the three patients after one year.

These authors concluded that a drug holiday had lasting beneficial effects and represented a realistic means of managing the complications of chronic levodopa therapy. It was however without benefit in 20 to $30 \%$ of the patients. A further report (Goetz, 1982) referred to the 9 month follow up study of this same group of patients.

In a research and clinical forum on Parkinson's disease (Marsden, 1981) there were several anecdotal references to drug holidays in occasional patients. One of the discussants (Lees) reflected upon the uniformly bad experiences with drug holiday. Marsden commented on the potential risks relative to the benefits. Stevens was impressed on some occasions by the better control that resulted after drug holiday. Godwin-Austen commented upon the use of weekend holidays and referred to one patient who improved over a three year follow up period with this method. i.e. five days with levodopa and two days, generally on the weekend, without levodopa.

A recent reference (Koller, 1982) suggests alternate day drug holidays. However this benefit proved to be useful only in the early stages of disease and did not significantly influence late stage problems.

We have had additional experience with a variety of similar programs of modified drug withdrawal including weekend or one or two day or alternate day withdrawals and found this to be of some value but it was not sufficient to reduce the more severe problems related to chronic levodopa administration. DeJong (1982) referred to the need for further study to find the optimum frequency and duration of drug holidays.

This paper reports a series of 31 holidays, the largest known group that had been studied using complete levodopa drug holiday as a therapeutic method. The reasons for inducing drug holiday consisted primarily in loss of drug effect in all of the 24 patients and 31 holidays. This resulted in severe gait disorders, rigidity, bradykinesia, tremor and marked limitations of activities of daily living. In addition, there were associated side effects or complications including on-off phenomenon in 9 patients, dyskinesia in 6, psychiatric disorders or pseudodementia in 10 patients, including 6 with hallucinations.

\section{METHODS}

All patients were treated in hospital because of the potential complications and the known fact that they would become worse and virtually helpless during the actual drug holiday. All levodopa compounds and dopamine agonists were discontinued over a period of five days or less. This was followed by a complete drug holiday from the dopamine substances for at least seven days in most cases and up to two weeks on occasions. In many patients, other antiparkinson medications were continued if they were already being administered, but no new drugs were introduced. All patients received active physiotherapy and respiratory therapy to prevent potential complications during the period of the holiday. Subcutaneous heparin for phlebitis prophylaxis was only occasionally used.

Upon restarting medication, the patient received one half of the quantity of the levodopa compound that had been used prior to the drug holiday. In several patients, levodopa compounds or agonists were gradually introduced with increments every second or third day. Gradual individualized additional increases and adjustments were made until a satisfactory response occurred. This was done slowly over a period of weeks often extending into the follow up period after discharge from hospital. Initially it appeared that some of the patients responded satisfactorily to a reduced quantity of levodopa; however as time went on, increased dosage was required in most patients which approximated the pre-holiday quantities.

All patients were evaluated by grading Parkinson signs of rigidity, tremor, bradykinesia, gait and mental status according to the Hoehn and Yahr classification, 0 being normal and 5 maximum disability. A modified Northwestern University Disability Scale (NUDS) was used relative to gait disorder and activities of daily living which included dressing, eating, speech etc. The complications which included on-off phenomena, dyskinesia and psychiatric disorders, pseudodementia and hallucinosis were also graded on a scale of 0 to 4 . Change of one category was regarded as mild, two categories moderate, three or four marked. Many of the patients were further evaluated on a 0 to 4 scale on an hourly basis relative to their mobility during their waking hours (Sandoz scale).

In this study, 24 patients had drug holidays. One individual had three holidays and 5 had two for a total of 31 holidays. Four other patients with drug holiday have not been included because of inadequate follow up to date. Most patients were in stage 4 with one stage 5 (Hoehn and Yahr), that is, all had fully developed severe, incapacitating disease. Three had previous thalamotomies. The average age was 63 years with a range of 40 to 78 . There were 14 male patients and 10 females. The average duration of disease was 10.3 years with a range of 3 to 21 years. The duration of levodopa therapy averaged 6.5 years with a range of 2 to 11 years.

\section{Results}

Improvement of 6 months or longer occurred in 14 of the 24 patients and in 15 of the 31 holidays, one patient having benefited on two occasions. There was total lack of response in two patients (Table 1). We discounted the short term improvements lasting less than six months. Some of these were of brief duration lasting for only a few weeks. In 14 patients with drug holidays, relapse occurred within the first six months. Nine patients had 
Table 1: Results of Drug Holiday

\begin{tabular}{lc}
\hline & No. of Holidays \\
\hline $\begin{array}{l}\text { Total Lack of Response } \\
\text { Response with Relapse in 1-6 Months }\end{array}$ & 2 \\
$\begin{array}{l}\text { Response for } 6-11 \text { Months } \\
(8 \text { relapsed, } 1 \text { improved) }\end{array}$ & 14 \\
$\begin{array}{l}\text { Response for } 12-25 \text { Months } \\
\text { with Maintained Improvement }\end{array}$ & 9 \\
\hline
\end{tabular}

a response that lasted for more than 6 months and up to one year, and 6 patients had improvement from 12 to 25 months. Several of the improved patients are still being followed and the full duration of benefit has not yet been determined.

In the group that responded for six months or longer, the following observations were noted (Table 2). There was significant improvement of motor function in 14 of 15 cases. Three of the patients had improvement in on-off phenomenon. Dementia or pseudodementia improved in 5 patients for over six months but in only 2 for over 12 months. Hallucinations cleared in two patients. In the 6 patients with the longest improvements, that is 12 months or more, (Table 3 ) 2 patients had motor improvement primarily. One had improvement relative to motor function and dementia and one with regard to motor function and on-off phenomenon. The longest period of improvement of 25 months involved motor function and hallucinations. One patient has had improved motor function for over 20 months. The degree of

Table 2: Symptoms Improved For Over 6 Months

\begin{tabular}{lc}
\hline \hline & No. of Patients \\
\hline Motor & 14 \\
On-Off & 3 \\
Dementia & 5 \\
Hallucinations & 2
\end{tabular}

These responses occurred in 15 of the 31 holidays and in 14 of the 24 patients

Table 3: Patients Showing Benefit for Over 12 Months Following Drug Holiday (6 of 31 Holidays in 24 patients)

\begin{tabular}{lclc}
\hline \hline Age/Sex & $\begin{array}{c}\text { Duration of } \\
\text { Benefit } \\
\text { (Months) }\end{array}$ & Function & $\begin{array}{c}\text { *Degree of } \\
\text { Improvement }\end{array}$ \\
\hline $68 / \mathrm{M}$ & $12+$ & Motor & 1 \\
$57 / \mathrm{M}$ & $12+$ & Motor & 2 \\
& & Dementia & 3 \\
$53 / \mathrm{F}$ & 20 & Motor & 2 \\
& & Halluc. & 3 \\
$78 / \mathrm{F}$ & $24+$ & Motor & 2 \\
& & On-Off & 2 \\
$63 / \mathrm{M}$ & $25+$ & Motor & 2 \\
& & Halluc. & 3 \\
$61 / \mathrm{F}$ & $20+$ & Motor & 2 \\
\hline
\end{tabular}

\footnotetext{
$* 1=$ Mild

2 = Moderate

$3=$ Marked
}

improvement was generally of clinical significance, ranging from mild to marked (that is, 1 to 3 category changes).

\section{Effect of Drug Holiday on Associated Problems}

On-off fluctuations occurred in 19 patients. Improvement of 24 months occurred in one, of 6 to 12 months in two and 1 to 6 months in 13. No improvement was noted in 3 individuals (Table 4).

Dementia or pseudodementia improved in 7 drug induced parkinsonian patients and in 6 others with a combination of a drug factor and degeneration. This was the initial response; however the long term follow up of 12 months or longer indicated that there was improvement in only two patients with dementia and in two others with hallucinations.

Dyskinesia occurred in a total of 6 patients; 5 improved for a short period only. In one there was no change and in one, dyskinesia developed for the first time upon reinstitution of therapy. No long term relief was obtained.

Table 4: Response of On-Off Fluctuations To Drug Holiday in 19 Patients

\begin{tabular}{lc}
\hline \hline Improvement & Number of Patients \\
Over 24 Months & 1 \\
$6-12$ Months & 2 \\
1 - 6 Months & 13 \\
No Improvement & 3 \\
\hline
\end{tabular}

\section{Problems and Complications}

(1) During the initial period of the drug holiday, all of the patients were virtually helpless and required total assistance while in hospital. An occasional patient showed initial transient improvement during the period of drug abstinence.

(2) There was increased stiffness, rigidity, tremor etc. during the drug holiday and the patients were basically unable to walk.

(3) One patient developed thrombophlebitis which subsequently recovered with anticoagulants. It should be noted that in the series of Weiner et al. (1980) subcutaneous heparin was used on a prophylatic basis. We did not regard this as necessary on a routine basis provided adequate physiotherapy was available.

(4) Patients were given specific respiratory exercises because of the risk of pneumonia. None of our patients developed this complication although it has been observed by others.

(5) Extensive nursing care was necessary in view of the patient's helplessness and risk potential.

\section{Discussion and Conclusions}

Twenty-four patients received 31 drug holidays from levodopa and other dopamine related substances including agonists. Improvement of significance occurred for a period of at least six months in 15 of the holidays. The majority of patients showed limited response of short duration and only six of the patients with drug holiday demonstrated response of consequence after a period of 12 months. This could not be related to age, sex, duration of disease or previous drug therapy. The eventual dosage of the medication was essentially unchanged in these patients although, initially, smaller quantities were sufficient. 
In general, improvement involved motor function, on-off phenomenon, dementia, pseudodementia and hallucinations.

The physiological or pharmacological basis for the effectiveness of a transient period of drug withdrawal is unknown. Alteration of dopaminergic receptor site sensitivity has been postulated. It has been suggested that long term dopaminergic stimulation results in postsynaptic supersensitivity, (Ptcoch and Marsden, 1977) postsynaptic desensitization, (Direnfeld et al., 1978) or presynaptic subsensitization (Mullen and Seeman, 1979).

It is presumed that the complete withdrawal of all levodopa compounds may influence receptor blockade by resensitizing the striatal dopamine receptors. In addition, there appears to be an alteration of denervation hypersensitivity with an improved response relative to on-off phenomenon and dyskinesia, although the latter complication was only transiently influenced by drug holiday (Rinne, 1980).

Hornykiewicz, (personal communication), has indicated that, in theory, the rationale of "drug holiday" as a means of allowing dopamine receptors to regain their previous responsiveness appears to be reasonable and valid. In his opinion, both the numbers and the physiological responses of receptors can be reduced following long term administration of dopamine substances. Following partial or complete drug withdrawal, there may be restoration of dopaminergic sensitivity. Goetz et al. (1982) are currently attempting to develop an accurate animal model for the study of the biochemical physiologic and receptor kinetic changes that occur after chronic levodopa exposure and transient drug interruptions.

On a theoretical basis, the beneficial effect of a levodopa drug holiday should become more significant after a more prolonged period. It is therefore conceivable, although not always practical, to postulate drug holidays of two weeks to two months rather than the more conventional concept of 5 to 7 days which may not allow sufficient time for a full receptor alteration and response.

Unfortunately in the majority of the patients, the improvement that was observed was of short duration with recurrence of similar problems within a period of weeks or months. This was somewhat shorter than the 6 or 9 month period observed by Koller et al. (1982) in their one year follow up series of 14 patients. (See also Weiner et al., 1980.)

Prophylatic care with maintenance of optimal low dosage of levodopa therapy is recognized as the best means of avoiding the development of some of the severe problems associated with long term administration. In addition, assessment of various forms of partial drug holiday and alternate day therapy may prove to be beneficial in a limited group of patients but this requires further trial. The suggestion of early interruption of therapy prior to the development of long term complications has been proposed (Koller et al., 1982), although this study has yet to be performed. Ultimately one must ask the patient, relatives and one's self whether a rather complex and somewhat unpredictable form of therapy such as levodopa drug holiday which will provide benefit in approximately $50 \%$ of individuals for an average of six months with a range of 0 to 2 years is worth the risk and inconvenience even without cost considerations.

It is concluded that drug holiday has an unpredictable and limited usefulness in Parkinson patients and should only be used selectively and cautiously for some severely disabled patients with intractable problems relative to motor function, on-off phenomenon, confusion and hallucinosis. Total drug withdrawal can only be carried out under close supervision in a hospital setting with adequate nursing and physiotherapy. It appears to be beneficial only in a minority of patients who have developed the severe intractable problems associated with prolonged levodopa therapy and who have become resistent to the conventional adjustments of therapeutic agents. The role of complete drug holiday has not been fully evaluated. In view of the limited and somewhat inconsistent studies to date, further cautious long term assessment is warranted.

\section{REFERENCES}

Barbeau A, McDowell FH (eds.) (1970) L-Dopa and Parkinsonism. 343-407. FA Davis Co. Phila.

DeJong RN, Currier RD (1982) Year Book of Neurology and Neurosurgery. Year Book Medical Publishers. Chicago. 154.

Direnfeld L, Spiro L, Marotta J, Seeman P (1978) The L-dopa on-off effect of Parkinson's disease: Treatment by transient drug withdrawal and dopamine receptor sensitization. Ann. Neurol, 4:473-475.

Goetz C, Tanner C, Klawans HL (1982) Drug Holiday in the Management of Parkinson's Disease. Clinical Neurology. 5: No. 4:351-364.

Kofman O (1971) Treatment of Parkinson's Disease with L-dopa. Can. Med. Assoc. J: 104:483-487.

Kofman O (1982) Drug Holiday in Parkinson's disease - A Long Term Appraisal, Abstracts 17th Congress of Neurological Sciences. Can. J. Neurol. Sci. 9:273.

Kofman O (1983) Complications of Therapy in Parkinson's disease. Can. Fam. Physician 29:87-91.

Koller WC (1982) Alternate Day Levodopa Therapy in Parkinsonism. Neurology, 32:324-326.

Koller WC, Weiner WD, Klawans HL et al. (1982) Complications of Chronic Levodopa Therapy: Long Term Efficiency of Drug Holiday. Neurology 31:473-476.

Marsden CD, Parkes JA (1976) On-Off Effects with Parkinson's disease on Chronic Levodopa Therapy, Lancet 1: 292-295.

Marsden CD (1981) Bromocriptine in Parkinson`s Disease. Research and Clinical Forums, Tunbridge Wells. England 3: No. 2:24-27.

Mullen P, Seeman P (1979) Pre-synaptic Subsensitivity as a Possible Basis For Sensitization by Long Term Dopamine Mimetics, Eur. J. Pharacol. 55:149-157.

Ptcoch CJ, Marsden CD (1977) Central Dopaminergic Receptor Supersensitivity and its Relevance to Parkinson's Disease, J. Neurol. Sci. 31:113-131.

Rinne VK (1980) Recent Advances in the Treatment of Parkinson's Disease, ACTA Nevol Scand. 62:103-121.

Sweet RD, Lee JE, Spiegel HE, McDowell F (1972) Enhanced Response to Low Doses of Levodopa After Withdrawal from Chronic Treatment. Neurology 22:520-525.

Weiner WJ, Perlik S, Koller WC, Nausieda PA, Klawans HL (1980) The Role of Drug Holiday in the Management of Parkinson's Disease. Neurology 30:1257-1261.

Yahr MD (1978) Overview of Present Day Treatment of Parkinson's Disease. J. Neural. Transm. 43:227-238. 